\title{
Adsorption of Polystyrene Sulfonate to the Air Surface of Water by Neutron Reflectivity
}

\author{
H. Yim, M. Kent*, A. Matheson \\ Dept. 1832, Sandia National Laboratories, Albuquerque, NM. \\ R. Ivkov, S. Satija \\ National Institute of Standards and Technology, Gaithersburg, MD. \\ J. Majewski, G. S. Smith \\ LANSCE, Los Alamos National Laboratories, Los Alamos, NM.
}

\begin{abstract}
The adsorption of the strong polyelectrolyte polystyrene sulfonate (PSS) to the air surface of dilute aqueous solutions was investigated as a function of molecular weight and salt concentration. Detailed segment profiles of the deuterated polymer were determined by neutron reflection. Surface activity was also examined through surface tension measurements. In general, the segment profiles are composed of a thin layer (10-20 $\AA$ thick) of high concentration at the air surface, followed by a distinct second layer of much lower segment concentration that extends to larger depths into the liquid. The high segment density at the air surface is due to a strong surface attraction, arising from the low surface tension of the PSS backbone relative to the surface tension of water. At low salt concentration, the profiles tend toward a single dense layer, suggesting that the chains lie nearly flat at the interface in that limit. The adsorbed amount increases with salt concentration, with a stronger dependence for higher molecular weight chains. The adsorbed amounts at the air/water interface are higher than reported previously for PSS adsorbed onto neutral solid surfaces, consistent with the fact that the air-liquid interface provides a stronger surface attraction. While the trends of adsorbed amount and layer thickness with salt concentration and molecular weight are in good agreement with numerical self-consistent field lattice calculations, the measured bilayer profiles are rather different from the smoothly decaying theoretical profiles. The surface tensions of the PSS solutions are significantly lowered relative to those of pure salt solutions. Combining the reflectivity and surface tension measurements, an approximately linear relationship is established between the surface pressure and the PSS adsorbed amount.
\end{abstract}

This work was supported by the U. S. Department of Energy under contract CE-AC0494AL85000. Sandia is a multiprogram laboratory operated by Sandia Corporation, a Lockheed Martin Company, for the United States Department of Energy. 


\section{DISCLAIMER}

This report was prepared as an account of work sponsored by an agency of the United States Government. Neither the United States Government nor any agency thereof, nor any of their employees, make any warranty, express or implied, or assumes any legal liability or responsibility for the accuracy, completeness, or usefulness of any information, apparatus, product, or process disclosed, or represents that its use would not infringe privately owned rights. Reference herein to any specific commercial product, process, or service by trade name, trademark, manufacturer, or otherwise does not necessarily constitute or imply its endorsement, recommendation, or favoring by the United States Government or any agency thereof. The views and opinions of authors expressed herein do not necessarily state or reflect those of the United States Government or any agency thereof. 


\section{DISCLAIMER}

Portions of this document may be illegible in electronic image products. Images are produced from the best available original document. 


\section{Introduction}

The adsorption of polyelectrolytes onto surfaces is important in many technologies. The adsorption of polyelectrolytes onto colloid surfaces plays a central role in the stabilization of emulsions in food, photographic, paint, water purification, flotation separations, enhanced oil recovery, and pharmaceutical industries. ${ }^{1,2}$ Adsorption of biological polyelectrolytes is important for understanding biochemical processes, and also for controlling fouling in biotechnological operations. ${ }^{3}$ From a fundamental point of view, it is interesting to investigate how the conformation of a polyelectrolyte is changed near an interface and the factors which control the conformation and the adsorbed amount. ${ }^{4}$

In this work we examine the adsorption of the strong polyelectrolyte polystyrene sulfonate (PSS) to the air surface of water. This system constitutes the unusual case of polyelectrolyte adsorption to a neutral surface with a large surface attraction described by the surface "chemical" adsorption parameter $\chi_{s}$. In general, surface attraction is determined by both electrostatic and chemical effects, and the combined effects are often described by an effective surface adsorption parameter $\chi_{\mathrm{s}}^{\text {eff } 4}$. For adsorption onto neutral solid surfaces, the surface attraction is determined by chemical effects alone $\left(\chi_{s}^{\text {eff }} \cong \chi_{s}\right)$, and $\chi_{s}$ is typically small. However, we show below that the values of $\chi_{s}$ are in general much larger at the air surface of aqueous solutions.

The activity of neutral polymers at the air surface of liquids has been studied previously using surface tension measurements, ${ }^{5-7} \mathrm{X}$-ray evanescent wave induced fluorescence, ${ }^{8-10}$ neutron reflectivity, ${ }^{10-13}$ surface light scattering, ${ }^{14,15}$ and ellipsometry. ${ }^{16}$ Either adsorption or depletion can occur if the surface tension of the polymer is much lower or much higher, respectively, than that of the solvent. For aqueous solutions, the adsorption energy per monomer is given by $a^{2}\left(\left(\gamma_{\text {air/water }}+X \gamma_{\text {monomer/water }}\right)-\left(\gamma_{\text {air/monomer }}+\right.\right.$ $\left.\gamma_{\text {monomerivater }}\right)$ ) where $a$ is the length of a monomer, $\gamma_{i}$ are the interfacial tensions and $\mathrm{X}$ is a factor greater than unity which depends upon the conformation of the polymer in the aqueous subphase. In general, the difference $\gamma_{\text {air }}$ water $-\gamma_{\text {airmonomer }}$ is much larger than the difference in the corresponding interfacial tensions at neutral solid substrates $\gamma_{\text {substratefwater }}$ -

$\gamma_{\text {substratemonomer }}$. Thus, while hydrophobic portions of the polymer will increase $\gamma_{\text {monomer/water }}$ and contribute to the adsorption energy at either air or solid interfaces, the adsorption energy is typically greater at the air surface due to the low surface tension of organic polymers relative to the surface tension of water. We show below that the strong $\chi_{s}$ leads to important effects in the proximal region.

Fleer $e t$ al have recently reviewed the theoretical work involving adsorption of polyelectrolytes, and outline a number of regimes. ${ }^{4}$ The main variables are the monomer- 
solvent interaction parameter $\chi$, the monomer-surface interaction parameter $\chi_{s}$, the molecular weight of the chains, the charge density on the adsorbing surface, the charge density on the chains, the polymer concentration, and the ionic strength or salt concentration. The present work concerns the case of strong polyelectrolytes, where the degree of dissociation does not vary with the local solution conditions. Numerical selfconsistent field (SCF) lattice calculations for this case have been reported by Van der Schee and Lyklema, ${ }^{17}$ Papenhuijezen, et al, ${ }^{18}$ and Bohmer et al. ${ }^{19}$ For the case of a neutral surface, as in the present work, adsorption is driven by $\chi_{\mathrm{s}}$ and opposed by the electrostatic interaction energy of the charges on the chains. Electrostatic effects typically dominate over the physicochemical effects embodied in $\chi_{\mathrm{s}}$. In that case, adsorption is negligible in the absence of salt. With increasing salt concentration, the electrostatic interactions become screened and at a particular point determined by the magnitude of $\chi_{s}$, chains begin to adsorb. The calculations showed that the first chains adsorb in a flat conformation because at low salt concentration the mutual repulsion between the charges on the chains inhibit loop formation. As a result of the flat conformation, the adsorbed amount does not depend upon molecular weight. With further increase in salt concentration, the chains become more flexible, more segments extend into the subphase, the adsorbed amount increases, and the molecular weight dependencies of the adsorbed amount and layer thickness increase. The predicted segment concentration profiles for high salt concentration are approximated by an exponential or power law decay from a maximum at the interface.

The effect of $\chi_{s}$ on the adsorption of strong polyelectrolytes has been addressed explicitly by Papenhuijezen, et al. ${ }^{18}$ The main effect is a strong increase in adsorbed amount with $\chi_{s}$. For high $\chi_{s}$, significant adsorption occurs even at very low salt concentration. The dependencies of adsorbed amount on salt concentration and molecular weight for high $\chi_{s}$ are comparable to those for low $\chi_{s}$, although the molecular weight dependence of the adsorbed amount is slightly weaker for higher $\chi_{s}$. Segment concentration profiles were not reported. Numerical SCF lattice calculations of the type described above have been performed for the adsorption of the milk proteins $\alpha_{s} 1^{-}$and $\beta$ casein to the air surface of water. ${ }^{20,21}$ In this case detailed segment profiles were reported. However, these proteins correspond to weak polyelectrolytes. Thus while the calculations are qualitatively informative in the context of the present system, they cannot be compared quantitatively to the present experimental data.

Previous experimental investigation of polyelectrolyte adsorption to the air surface of water has involved surface tension measurements, ${ }^{22-25}$ direct detection of adsorbed amounts using radioactive labelling, ${ }^{25-27} \mathrm{X}$-ray and neutron reflectivity, ${ }^{28-31}$ and surface light scattering. ${ }^{32}$ Frommer and Tanner measured the adsorbed amount of DNA at the air 
surface of water by tritium-labelling. ${ }^{25}$ Adsorption was observed to increase with increasing salt concentration. No change in surface tension was observed, even for cases of very strong adsorption. This was explained in terms of the balancing effects of a negative surface excess of salt and a positive surface excess of polyelectrolyte using the generalized Gibbs adsorption equation. We report a similar observation in the present system. However, our interpretation is quite different. We show below that the surface tension of the pure salt solution increases with salt concentration, and that polyelectrolyte adsorption indeed results in significant surface pressure. Okubo, ${ }^{22}$ Okubo and Kobayashi, ${ }^{24}$ and Caminati and Gabrielli ${ }^{23}$ examined the surface tension of various aqueous polyelectrolyte solutions (including PSS) as a function of polyelectrolyte concentration. These studies were all conducted at low salt concentration. Adsorbed amount and polymer conformations were inferred from decreases in surface tension.

Other experimental work has involved mainly weak polyelectrolytes. Several groups have studied the adsorbed segment concentration profile of the milk protein $\beta$ casein at the air surface of water by X-ray and neutron reflection. ${ }^{28-30}$ All groups reported a thin segment-rich layer at the surface. One group reported a decrease in segment concentration from the surface according to a power law, ${ }^{30}$ whereas another group reported a distinct, diffuse second layer extending into the aqueous subphase. ${ }^{28,29}$ Vaynberg, et al examined the adsorbed segment profile of gelatin at the air surface of water by $\mathrm{X}$-ray reflectivity, where heavy counterions were used to provide X-ray contrast. ${ }^{31} \mathrm{~A}$ bilayer profile was again observed, although the signal was quite weak. NR and XR have also been used to study the adsorption of the water-soluble polymer $\mathrm{PEO}^{13,33}$ and block copolymers with hydrophobic and hydrophilic blocks ${ }^{34,35}$ to the air surface of water.

In the present work the adsorbed segment concentration profile of deuteriumlabelled PSS is determined directly by neutron reflectivity as a function of molecular weight and salt concentration för dilute PSS concentration. Much greater scattering contrast is obtained with deuterium-labelled PSS in a mostly $\mathrm{H}_{2} \mathrm{O}$ subphase than in the previous $\mathrm{X}$-ray and neutron reflectivity studies of polyelectrolyte adsorption at the liquid-air interface mentioned above. This allows greater detail in the profile to be obtained as well as investigation of the detailed segment profile over a wider range of adsorbed amount. The surface tension was also examined along with the measurement of adsorbed segment profiles. This provides insight into the net affect of polyelectrolyte adsorption on the surface free energy, as in previous work involving $\mathrm{DNA}^{25}$ and $\beta$-casein. ${ }^{29}$ The rheological properties and the static properties of PSS in solution have been reported previously. ${ }^{36-40}$ 


\section{Experimental}

\section{Materials}

Two deuterated sodium polystyrene sulfonate samples were used. PSS56, with molecular weight of $56,100 \mathrm{~g} / \mathrm{mol}$ (excluding $\mathrm{Na}^{+}$counter ions) and $\mathrm{M}_{w} / \mathrm{M}_{\mathrm{n}}=1.06$, was obtained from Polymer Source (Quebec, Canada). ${ }^{41}$ For the second sample, d-PS of molecular weight $708,000 \mathrm{~g} / \mathrm{mol}$ and $M_{w} / M_{n}=1.03$ was obtained from Pressure Chemical Co. and sulfonated using the method of Vink. ${ }^{42}$ One gram of a solution of d-PS dissolved in $100 \mathrm{ml}$ of cyclohexane was added dropwise to a solution of $6 \mathrm{~g}$ of $\mathrm{P}_{2} \mathrm{O}_{5}$ in $27 \mathrm{ml}$ of $\mathrm{H}_{2} \mathrm{SO}_{4}$ at $50^{\circ} \mathrm{C}$. The solution was stirred for $60 \mathrm{~min}$ and allowed to stand for an additional $60 \mathrm{~min}$ without stirring. After the solution was cooled in an ice bath, $17 \mathrm{~g}$ of frozen $\mathrm{H}_{2} \mathrm{O}$ were added. In this process a yellowish white sticky mass was obtained. The product was washed with distilled water several times, dissolved in $300 \mathrm{ml}$ of water, and then neutralized by adding sodium methoxide. Finally, the product was precipitated by adding excess $\mathrm{NaCl}$ and isolated by centrifuge. The final product was washed with distilled water several times to remove excess salt and used without further purification. We refer to the second sample by the designation PSS1150, which corresponds to the molecular weight in $\mathrm{kg} / \mathrm{mol}$ excluding $\mathrm{Na}^{+}$counter ions. The sulfonization level of both samples was roughly $90 \%$ determined by ${ }^{13} \mathrm{C}$ NMR. PSS56 was white, while PSS1150 had a slightly yellowish tinge. For the reflectivity work, $\mathrm{KCl}(99+\%$, Aldrich) was used. For surface tension measurements performed subsequent to the reflectivity work, a higher grade of $\mathrm{KCl}$ (99.999\%, Aldrich) was used.

\section{Methods.}

For each solution, the d-PSS sample was dissolved in a $\mathrm{H}_{2} \mathrm{O}_{2} \mathrm{D}_{2} \mathrm{O}$ mixture $(\mathrm{v} / \mathrm{v}$ $0.843 / 0.157)$ at dilute concentration $(0.001 \mathrm{~g} / \mathrm{ml})$, and then the desired amount of $\mathrm{KCl}$ was added. After mixing, the solutions were allowed to equilibrate for $\sim 6 \mathrm{hrs}$ prior to use. The composition of the aqueous solvent was chosen to optimize the neutron scattering contrast while maintaining a critical edge for total reflection. The neutron scattering length density (SLD) of the pure subphase was $0.530 \times 10^{-6} \AA^{-2}$, which corresponds to a critical edge for total reflection at $q_{c}=0.0052 \AA^{-1}$. Fresh solution was prepared for each reflectivity experiment. The solution was contained in a Teflon trough at room temperature. Roughly 20 minutes passed between the time the solution was poured into the trough and the beginning of data collection. 
The neutron reflectivity (NR) measurements were performed on the NG7. reflectometer at NIST. A fixed wavelength of $4.75 \AA$ was used. The reflectivity data were analyzed by two methods. In method I, the SLD profile was approximated with a series of 3 or 4 slabs of constant SLD. The interfaces between the slabs were smeared by dividing the interface region into many smaller slabs and using an error function to describe a smooth variation in SLD. The thickness and SLD of each primary slab and the interface widths between the primary slabs were adjustable parameters. The number of adjustable parameters ranged from 5 to 7 . In method II, the SLD profile was approximated by dividing the entire profile into $2 \AA$ thick slabs and varying the SLD according to various functional forms. The number of adjustable parameters was either 4 or 5 depending upon the functional form. In each case the reflectivity was calculated from the stack of slabs using the optical matrix method. ${ }^{43,44}$ Best-fit profiles are determined by minimization of least squares.

After collecting the reflectivity data, the surface tension was measured by the Wilhelmy plate technique using filter paper and a NIMA film balance. Additional surface tension measurements subsequent to the reflectivity work were performed in our lab with a sand-blasted platinum plate and a Q11 force transducer from Hottinger Baldwin Measurements.

\section{Results and Discussion}

NR data for solutions of PSS1150 and PSS56 at various $\mathrm{KCl}$ concentrations are shown in Figure 1a and Figure 2a, respectively. The data cover nearly six orders of magnitude in reflectivity and are displayed as reflectivity $\times q^{4}$ to compensate for the $q^{-4}$ decay due to the Fresnel law. The reflectivity data for the pure $\mathrm{H}_{2} \mathrm{O} / \mathrm{D}_{2} \mathrm{O}$ mixture $\left(\mathrm{R}_{\mathrm{o}}\right)$ are also shown. Notice that for the highest salt concentrations, $R / R_{o}$ exceeds 10 . This constitutes a much larger signal than in previous reflectivity studies of polyelectrolytes at the air-water interface, where $\mathrm{R} / \mathrm{R}_{0}$ was typically less than $2 .^{28-31}$ The curves through the data correspond to the segment concentration profiles obtained using analysis method $I$. The profiles are shown in Figure $1 \mathrm{~b}$ and Figure $2 \mathrm{~b}$. Segment concentration profiles obtained using analysis method II are shown in Figure 1c and Figure 2c. For PSS56, the functional form of method II consisted of the sum of two parabolas combined with an exponential tail. For PSS1150, the functional form consisted of a single parabola followed by an exponential decay. For both samples, the quality of the best-fit was comparable for the two analysis methods. Segment concentrations were calculated from the SLD values assuming a uniform distribution of $\mathrm{K}^{+}$and $\mathrm{Cl}^{-}$ions, and $\mathrm{Na}^{+}$counter ion condensation on 
the PSS chains. The presence of $\mathrm{KCl}$ results in only a modest increase in the SLD of the subphase (subphase with the highest $\mathrm{KCl}$ concentration of $2.50 \mathrm{M}$ has a SLD of $0.68 \times 10^{-6}$ $\AA^{-2}$ ), and so uncertainty regarding the detailed distribution of $\mathrm{K}^{+}$and $\mathrm{Cl}^{-}$ions within the surface layer only weakly impacts the calculated segment concentration profiles. Also, exchange of $\mathrm{K}^{+}$for $\mathrm{Na}^{+}$counter ions would have only a very small effect on the calculated concentration profiles. In the model profiles, we assume that the roughness of the air surface is controlled by capillary waves and that it remains constant at $3 \AA .^{45,46}$ The calculated SLD of each subphase $\left(\mathrm{H}_{2} \mathrm{O} / \mathrm{D}_{2} \mathrm{O}\right.$ mixture $\left.+\mathrm{KCl}\right)$ was used without correction in the fitting.

For both samples, the profiles are found to consist of a high segment concentration immediately at the air surface followed by a second, more extended layer of much lower segment concentration. The layer of high segment concentration at the surface is due to the strong attraction of PSS to the air surface arising from the large value of $\gamma_{\text {air/water }}-\gamma_{\text {air/monomer }}$. A surface layer of high segment concentration comparable to that reported here resulted from numerical SCF calculations modeling the adsorption of $\alpha_{\mathrm{s} 1^{-}}$and $\beta$-casein at the air surface of water. ${ }^{20,22}$ This was due to a strong attraction for the surface (large $\chi_{s}$ ) assigned to the apolar segments of the protein. In general a large $\chi_{s}$ will result from the low surface energy of organic monomers relative to water, and thus a thin layer of high segment concentration is expected to be a general feature of all organic water soluble polymers. Bilayer profiles qualitatively similar to those in the present case were reported previously for gelatin ${ }^{31}$ and for polyethylene oxide at the air surface of water. ${ }^{13,33}$ These results support the universality of a surface layer of high segment concentration for organic-based polymers in an aqueous subphase. We note however, that such bilayer profiles are not limited to the air-water interface, as similar bilayer profiles have also been reported for $\beta$ casein at the interface between water and self-assembled monolayers of octadecyltrichlorosilane on silicon ${ }^{47}$ and for PSS adsorbed from aqueous solutions onto weakly charged PS latex particles by small angle neutron scattering. ${ }^{48}$ In these cases, hydrophobic interactions or electrostatic interactions with the surface apparently also lead to fairly strong surface attraction.

Both analysis methods indicate that a distinct second layer is required in the segment concentration profiles. Profiles with a high segment concentration at the air surface that decay smoothly to a low bulk value do not give an acceptable fit to the data. This is shown in Figure $3 \mathrm{a}$ and Figure 3b for the PSS1150 sample, and in Figure $4 \mathrm{a}$ and Figure $4 \mathrm{~b}$ for the PSS56 sample. Figure $3 \mathrm{a}$ shows the reflectivity data for a $\mathrm{KCl}$ concentration of $2.50 \mathrm{M}$ along with best-fits using analysis method II. Two functional forms are shown. The first form consists of a single parabola with an exponential tail 
where the derivative is constrained to vary smoothly from the parabola to the exponential. The second functional form is the same as the first except that the derivative is not constrained to vary smoothly from the parabola to the exponential. The best-fit profiles are shown in Figure $3 \mathrm{~b}$. The smoothly decaying profile is clearly inadequate as indicated by the poor fit in Figure 3a. We note that a distinct second layer is also required for the PSS56 sample, although the functional form for the extended layer is quite different from that for the PSS1150 sample. Figure 4a shows the reflectivity data for a $\mathrm{KCl}$ concentration of $2.50 \mathrm{M}$ along with best-fits using analysis method $\mathrm{I}$ and i) a functional form consisting of the sum of two parabolas combined with an exponential tail, and ii) a form consisting of a single parabola with an exponential tail where the derivative was constrained to vary smoothly from the parabola to the exponential. The best-fit profiles are shown in Figure $4 \mathrm{~b}$. The smoothly decaying profile is again clearly inadequate as indicated by the poor fit in Figure 4a.

The present profiles showing a distinct second layer are similar to the profiles reported by Atkinson, et al for adsorption of $\beta$-casein to the air surface of water by neutron reflection, ${ }^{29}$ but contrast with the experimental profiles reported by Harzallah, et al ${ }^{30}$ and with numerical SCF calculations for the same sysem. ${ }^{21}$ Both the results of Harzallah, et al and the numercial SCF calculations are consistent with a smooth decay (approximated by a power law or exponential) from the surface layer, without a clear distinction between regions of different concentration variation. To our knowledge, no SCF calculations of profiles have been reported for the case of a strong polyelectrolyte and large $\chi_{s}$.

The strong increase in reflectivity with salt concentration shown in Figure 1a and Figure 2a corresponds to an increase in the segment concentration of both layers. At low salt concentration $(0.137 \mathrm{M})$, the profile consists mainly of the surface layer. From the small dimension of the surface layer (10-20 $)$, the extended chains appear to lie nearly flat at the surface. This conclusion is contrary to that reported previously by Gabrielli and Caminati for PSS at the air-water interface based on surface tension measurements. ${ }^{23}$ However, nearly flat configurations for strongly adsorbed polyelectrolytes at low salt concentration were reported previously for PSS adsorbed from water onto polystyrene latex particles by small angle neutron scattering ${ }^{48}$ and for $\beta$-casein adsorbed to the airwater interface by neutron reflection. ${ }^{28}$ A nearly flat configuration at low salt concentration is also consistent with the results of numerical SCF lattice calculations. ${ }^{4,17-19}$ The chains are rather sparsely packed in the surface layer, as the strong attraction to the surface is balanced by strong charge repulsion. For $0.137 \mathrm{M}$, the area per molecule is $150 \mathrm{~nm}^{2}$ for PSS56, and $2800 \mathrm{~nm}^{2}$ for PSS1150. With increasing salt concentration, the second layer becomes increasingly prominent. At the highest salt concentration $(2.50 \mathrm{M})$ the segment 
concentration in the surface layer is very high for both molecular weights, reaching roughly 0.7. The profile extends to a depth of $\sim 500 \AA$ for PSS 1150 and to $\sim 150 \AA$ for PSS56.

The dependence of the adsorbed amount on molecular weight and salt concentration is plotted in Figure 5. The adsorbed amount $\Gamma$ is given by $\rho \int \phi(z) d(z)$, where $\rho$ is the density of d-PSS and $\phi(z)$ is the volume fraction of adsorbed chain segments. ${ }^{49}$ The reflectivity signal was insufficient to obtain the adsorbed amount for $0.014 \mathrm{M} \mathrm{KCl}$. The adsorbed amount is plotted versus the square root of salt concentration, following the prediction of a linear relationship originally made by Hesselink ${ }^{50}$ and subsequently supported by numerical SCF calculations. ${ }^{4,19}$ The present data are consistent with this relationship, in agreement with studies of PSS adsorption onto neutron solid surfaces. ${ }^{4,51,52,53}$ No dependence of adsorbed amount on molecular weight is detected at $0.137 \mathrm{M} \mathrm{KCl}$, but a significant dependence on molecular weight occurs at the higher salt concentrations. We note that the molecular weight dependence of the adsorbed amount over the entire range of salt concentration examined is slightly weaker than reported for PSS adsorption onto uncharged solid surfaces (polyoxymethylene or silica at $\mathrm{pH} 2$ ).,51,52 This is consistent with a stronger $\chi_{s}$ for the air-water interface compared to the neutral solid-water interface. For stronger $\chi_{s}$ a higher proportion of the segments remain on the surface, resulting in a weaker dependence of adsorbed amount on molecular weight. ${ }^{18}$

An important result of the larger $\chi_{s}$ at the air-water interface is that the adsorbed amount of PSS is larger than observed on neutral solid surfaces over the entire range of salt concentration examined. The adsorbed amount of PSS on polyoxymethylene or silica at $\mathrm{pH}$ $=2$ (neutral surfaces) becomes vanishingly low at $\mathrm{NaCl}$ concentration below $0.1 \mathrm{M}$, irrespective of the molecular weight of PSS, ${ }^{4,51,52}$ whereas in the present system the adsorbed amount is quite significant $\left(\sim 0.7 \mathrm{mg} / \mathrm{m}^{2}\right)$ at $0.137 \mathrm{M} \mathrm{KCl}$. At a $\mathrm{NaCl}$ concentration of $1.0 \mathrm{M}$, the adsorbed amount of PSS on polyoxymethylene or silica at $\mathrm{pH}$ $=2$ is $\sim 0.5 \mathrm{mg} / \mathrm{m}^{2}$ for $31 \mathrm{~K}$, and $\sim 1 \mathrm{mg} / \mathrm{m}^{2}$ for $690 \mathrm{~K} \mathrm{PSS}$, respectively, ${ }^{4,51,52}$ and that for $350 \mathrm{~K}$ PSS on platinum is $0.3 \mathrm{mg} / \mathrm{m}^{2}$. ${ }^{52}$ In the present system the adsorbed amounts at 1 $\mathrm{M} \mathrm{KCl}$ are much higher, with values of $-1.5 \mathrm{mg} / \mathrm{m}^{2}$ and $2.1 \mathrm{mg} / \mathrm{m}^{2}$ for $56 \mathrm{~K}$ and $1150 \mathrm{~K}$ PSS, respectively. The adsorbed amount in the present work is comparable to that reported for PSS adsorption onto lightly charged PS latex particles. ${ }^{48}$

The effect of salt concentration on the thickness of the adsorbed layer is shown in Figure 6. There are two competing effects of salt concentration on the thickness of the adsorbed layer. First, the adsorbed amount increases with salt concentration, which tends to increase the thickness of the adsorbed layer. However, salt also screens the interaction between charges on the chains and effectively decreases the solvent quality, which leads to decreased thickness. The latter effect has been examined in detail elsewhere for the present 
system. ${ }^{37,38}$ In that work, dynamic light scattering was used to determine the dependence of the self-diffusion coefficient (D) on degree of polymerization $(\mathrm{N})$ as a function of salt concentration. With no added salt, the solvent quality is better than that for PS in toluene, i.e. $\mathrm{D} \sim \mathrm{N}^{-\mathrm{x}}$, where $\mathrm{x}>0.6$. The good solvent condition $\mathrm{D} \sim \mathrm{N}^{-0.6}$ occurs at $0.15 \mathrm{M}$ $\mathrm{NaCl}{ }^{37}$ The theta solvent condition $\mathrm{D} \sim \mathrm{N}^{-0.5}$ occurs at a $\mathrm{KCl}$ concentration of $3.1 \mathrm{M}^{37,38}$ These two competing effects of increased adsorption and decreasing solvent quality explain the trend in thickness with salt concentration shown in Figure 6. At lower salt concentration $(\leq 1 \mathrm{M})$, the dominant effect on the thickness is the increase in adsorbed amount. As more chains adsorb to the surface with increasing salt concentration, more segments extend into the subphase liquid and the layer thickness increases. Correspondingly, the molecular weight dependence of the layer thickness increases as well. However, once the salt concentration exceeds $1.0 \mathrm{M}$, the thickness becomes more strongly affected by the decrease in solvent quality. For both samples, the thicknesses decreases above $1.0 \mathrm{M}$ salt concentration, which is consistent with the fact that the solvent quality is intermediate between good and theta conditions. We note that the PSS chains are not collapsed at the surface at $2.50 \mathrm{M} \mathrm{KCl}$, which is consistent with the fact that the solvent quality is still slightly better than theta at this salt concentration. Auroy et al ${ }^{54,55}$ report that a PSS end-grafted brush shrinks continuously but does not collapse, even at $5 \mathrm{M} \mathrm{NaCl}$.

The present results for adsorbed amount and layer thickness are in good agreement with theoretical expectations. In the limit of low salt concentration, electrostatic effects are strong and the accumulation of charge density at the surface is unfavorable. However, for sufficiently high $\chi_{s}$ some degree of chain adsorption is still expected, and indeed this is observed in the present case. In the limit of high $\chi_{s}$ and low salt concentration, the chains are expected to lie flat. Consequently, no dependence of thickness or adsorbed amount on molecular weight is predicted in that limit. ${ }^{4}$ While the data tend toward this limit, this limit is not attained over the experimentally accessible range as a diffuse second layer is detected even at $0.137 \mathrm{M} \mathrm{KCl}$. At still lower salt concentration, the reflectivity signal is too weak to detect the polymer conformation. Based on model calculations, submonolayer coverage of d-PSS segments lying flat on the surface is not detectable in this experiment. With increasing salt concentration, the charges are screened, the adsorbed amount increases, and more segments extend into the subphase. This leads to an increasing molecular weight dependence of the adsorbed amount with salt concentration. ${ }^{4,51,52}$ Whereas the trends of adsorbed amount and layer thickness on molecular weight and salt concentration are consistent with prediction, agreement is not obtained for the detailed shape of the profile. In particular, the presence of the distinct second layer contrasts with the smoothly decaying 
theoretical profiles from numerical SCF calculations for weak polyelectrolytes at high $\chi_{s}^{21}$ : or strong polyelectrolytes at low $\chi_{s}{ }^{4}$

The surface tension of each solution was measured following collection of the reflectivity data. For both samples, little change $(<1 \mathrm{dyn} / \mathrm{cm})$ in surface tension was detected over the entire range of salt concentration examined. This observation is similar to that reported for DNA in aqueous salt solutions by Frommer and Miller. ${ }^{25}$ Subsequent to the reflectivity experiments, further surface tension measurements were performed in our laboratory for aqueous $\mathrm{KCl}$ solutions of the PSS1150 sample at $0.001 \mathrm{~g} / \mathrm{ml}$ and also for pure aqueous $\mathrm{KCl}$ solutions. These data, covering the range of $\mathrm{KCl}$ concentration examined in the reflectivity experiments, are plotted in Figure 7. This plot shows the very small change in surface tension that occurs with increasing salt concentration. In addition, it shows that the surface tension of a pure salt solution increases substantially with $\mathrm{KCl}$ concentration. The latter effect is well known, however its origin has not yet been clearly resolved. ${ }^{56.57}$ From Figure 7, it is clear that adsorption of PSS indeed leads to a significant lowering of the surface tension. The surface pressure due to the adsorbed polymer is given by the difference in surface tension for the salt solutions with and without the polymer. From the data in Figure 7, the surface pressure due to PSS1150 approaches 6 dyn/cm at 3 $\mathrm{M} \mathrm{KCl}$. In Figure 8, the surface tension data in Figure 7 are combined with the adsorbed amounts determined from the reflectivity to determine the relationship between surface pressure and adsorbed amount of PSS1150. It must be remembered that salt concentration is the independent variable and varies along the abscissa in Figure 8. The relationship in Figure 8 would be very difficult to obtain at the solid/liquid interface, and to our knowledge this is the first time such a relationship has been established. Combined with the conformational information in Figures 1-3, these data provide a strong test for theories of polyelectrolyte adsorption.

In summary, we have investigated the detailed segment profile for deuterated polystyrene sulfonate adsorbed to the air surface of dilute aqueous solutions by neutron reflection. Strong contrast from deuterium labeling allows the segment profile to be examined in detail over a range of adsorbed amount. In the limit of low salt concentration, the profile tends toward a conformation consisting of mainly a thin dense surface layer, i.e. mostly trains with few segments extending into the subphase. At higher salt concentration, we find a bilayer profile with a thin layer of very high segment concentration at the air surface and a distinct second layer of much lower segment concentration which extends well into the subphase. The form of the second, extended layer is different for high and low molecular weight samples, where a parabola with an exponential tail is an adequate description for low $\mathrm{N}$ and a simple exponential decay is an adequate description for high $\mathrm{N}$. 
The high segment concentration at the surface is due to a strong attraction resulting from the , low surface tension of the PSS backbone relative to that of water. The strong segment attraction to the surface leads to increased adsorption relative to that at neutral solid surfaces over the entire range of salt concentration. Strong segment-surface attraction is expected to be a general feature for organic-based water soluble polymers adsorbed to the air surface of aqueous solutions. The trends in adsorbed amount and layer thickness with salt concentration and molecular weight are in good agreement with the predictions of numerical SCF theory, while the form of the distinctly bilayer profiles contrasts with the more smoothly decaying theoretical profiles. The surface tension of the PSS solutions is significantly lowered relative to that of the pure salt solutions. The adsorbed amount and surface pressure both increase with salt concentration, and an approximately linear relationship is established between the adsorbed amount and the surface pressure.

\section{Acknowledgement}

This work was supported by the U.S. Department of Energy under contract CE-AC0494AL85000. Sandia is a multiprogram laboratory operated by Sandia Corporation, a Lockheed Martin Company, for the United States Department of Energy. 


\section{References and Notes}

1. Napper, D. H. Polymeric Stabilization of Colloid Dispersions; Academic Press: New York, 1983.

2. Dickenson, E. Current Opinion in Colloid \& Interface Science 1998, 3, 633.

3. Fukuzaki, S.; Urano, H.; Nagata, K. J. Ferment. and Bioeng. 1996, 81, 163.

4. Fleer, G. J.; Cohen-Stuart, M. A.; Scheutjens, J. M. H. M.; Cosgrove, T.; Vincent, B. Polymers at Interfaces; Chapman \& Hall: London, 1993.

5. Ober, R.; Paz, L.; Taupin, C.; Pincus, P.; Boileau, S. Macromolecules 1983, 16, 50.

6. di Meglio, J. M.; Ober, R.; Paz, L.; Taupin, C.; Pincus, P. J. Phys. 1983, 44, 1035.

7. di Meglio, J. M.; Taupin, C. Macromolecules 1989, 22, 2388.

8. Barton, S. W.; Bosio, L.; Cortez, R.; Rondelez, F. Europhys. Lett. 1992, 17, 401.

9. Kent, M.; Bosio, L.; Rondelez, F. Macromolecules 1992, 25, 6231.

10. Guiselin, O.; Lee, L. T.; Farnoux, B.; Lapp, A. J. Chem. Phys. 1991, 95, 4632.

11. Lee, L. T.; Guiselin, O.; Farnoux, B.; Lapp, A. Macromolecules 1991, 24, 2518.

12. Lee, L. T.; Guiselin, O.; Lapp, A.; Farnoux, B.; Penfold, J. Phys. Rev. Lett. 1991, $67,2838$.

13. Rennie, A. R.; Crawford, R. J.; Lee, E. M.; Thomas, R. K.; Crowley, T. L.; Roberts, S.; Qureshi, M. S.; Richards, R. W. Macromolecules 1989, 22, 3466.

14. Sauer, B. B.; Yu, H. Macromolecules 1989, 22, 780.

15. Kawaguchi, M.; Sauer, B. B.; Yu, H. Macromolecules 1989, 22, 1735.

16. Langevin, D. Langmuir (submitted)

17. Van der Schee, H. A.; Lyklema, J. J. Phys. Chem. 1984, 88, 6661.

18. Papenhuijzen, J.; Van der Schee, H. A.; Fleer, G. J. J. Colloid Interface Sci. 1985, 104,540 .

19. Bohmer, M. R.; Evers, O. A.; Scheutjens, J. M. H. M. Macromolecules 1990, 23, 2288. 
20. Leermakers, F. A. M.; Atkinson, P. J.; Dickinson, E.; Horne, D. S. J. Chem. Soc. Faraday Trans. 1996, 178, 681.

21. Dickinson, E.; Horne, D. S.; Pinfield, V. J.; Leermakers, F. A. M. J. Chem. Soc. Faraday Trans. 1997, 93, 425.

22. Okubo, T. J. Colloid Interface Sci. 1988, 125, 386.

23. Gabrielli, G.; Caminati, G. Colloids and Surfaces A 1993, 70, 1.

24. Okubo, T.; Kobayashi, K. J. Colloid Interface Sci. 1998, 205, 433.

25. Frommer, M. A.; Miller, I. R. J. Phys. Chem. 1968, 72, 2862.

26. Graham, D. E.; Phillips, M. C. J. Colloid Interface Sci. 1979, 70, 415.

27. Hunter, J. R.; Kilpatrick, P. K.; Carbonnell, R. G. J. Colloid Interface Sci. 1991, $142,429$.

28. Dickinson, E.; Horne, D. S., Phipps, J. S.; Richardson, R. M. Langmuir 1993, 9, 242.

29. Atkinson, P. J.; Dickinson, E.; Horne, D. S.; Richardson, R. M. J. Chem. Soc. Faraday Trans. 1995, 91, 2847.

30. Harzallah, B.; Angie-Beghin, V.; Douillard, R.; Bosio, L. Int. J. Biol. Macromol. $1998,23,73$.

31. Vaynberg, K. A.; Wagner, N. J.; Ahrens, H.; Helm, C. A. Langmuir 1999, 15, 4687.

32. Gan, C. S. ;Yu, H.; Żografi, G. J. Colloid Interface Sci. 1994, 162, 214.

33. Lu, J. R.; Su, T. J.; Thomas, R. K.; Penfold, J.; Richards, R. W. POLYMER 1996, $37,109$.

34. An, S. W.; Thomas, R. K.; Baines, F. L.; Billingham, N. C.; Armes, S. P.; Penfold, J. Macromolecules 1998, 31, 7877.

35. Millet, F.; Nedyalkov, M.; Renard, B.; Perrin, P.; Lafuma, F.; Benattar, J. J. Langmuir 1999, 15, 2112.

36. Boris, D. C.; Colby, R. H. Macromolecules 1998, 31, 5746. 
37. Takahashi, A.; Kata, T.; Nagasawa, M. J. Phys. Chem. 1967, 71, 2001.

38. Wang, L.; Yu, H. Macromolecules 1988, 21, 3498.

39. Spiteri, M. N.; Boué, F.; Lapp, A.; Cotton, J. P. Phys. Rev. Lett. 1996, 77, 5218.

40. Hirose, E.; Iwamoto, Y.; Norisuye, T. Macromolecules 1999, $32,8629$.

41. Use of a commercial product does not imply recommendation or endorsement by NIST, nor does it imply that the product is necessarily the best available.

42. Vink, H. Makromol. Chem. 1981, 182, 279.

43. Russell, T. P. Mater. Sci. Rep. 1990, 5, 171.

44.Penfold, J.; Thomas, R. K. J. Phys.: Condens. Matter 1990, 2, 1369.

45.Braslau, A.; Deutsch, M.; Pershan, P.S.; Als-Nielsen, J.; Bohr, J. Phys. Rev. Lett. 1985, 54, 114.

46. Braslau, A.; Pershan, P.S.; Swislow, G.; Ocko, B.; Als-Nielsen J. Phys. Rev. A $1988,38,2457$.

47. Fragneto, G.; Thomas, R. K.; Rennie, A. R.; Penfold, J. Science 1995, 267, 657.

48. Cosgrove, T.; Obey, T. M.; Vincent, B. J. Colloid Interface Sci. 1986, 111, 409.

49. Two assumptions are made to calculate the adsorption amount of d-PSS. First, the density of d-PSS is calculated by assuming that the volume of d-PSS is same as that of h-PSS. The density of h-PSS is known to be $0.801 \mathrm{~g} / \mathrm{cm}^{3}$ (from Aldrich). The density of d-PSS is $0.828 \mathrm{~g} / \mathrm{cm}^{3}$. Second, salts are assumed to be uniformly distributed in the solution and to be excluded from the volume occupied by d-PSS.

50. Hessëlink, F. Th., J. Colloid Interface Sci., 1977, 60, 448.

51. Marra, J.; van der Schee, H. A.; Fleer, G. J.; Lyklema, J. in Adsorption from Solution; Ottewill, R. H.; Rochester, C. H.; Smith, A. L., Eds.; Academic Press: $1983,245$.

52. Papenhuijzen, J.; Fleer, G. J.; Bijsterbosch, B. H. J. Colloid Interface Sci. 1985, 104, 530. 
53. Takahashi, A.; Kawaguchi, M.; Hayashi, K.; Kato, T. ACS Symp. Ser. 1984, 240, 39.

54. Mir, Y.; Auroy, P.; Auvray, L. Phys. Rev. Lett. 1995, 75, 2863.

55. Tran, Y.; Auroy, P.; Lee, L. T. Macromolecules, submitted.

56. Weissenborn, P. K.; Pugh, R. J. J. Colloid Interface Sci. 1996, 184, 550.

57. Matubayasi, N.; Yamamoto, K.; Yamaguchi, S.-I.; Matuso, H.; Ikeda, N. J. Colloid Interface Sci. 1999, 214, 101. 


\section{Figure Captions}

Figure 1. (a) Neutron reflectivity data from dilute PSS1150 solutions $(0.001 \mathrm{~g} / \mathrm{ml})$ with varying $\mathrm{KCl}$ concentration: pure $\mathrm{H}_{2} \mathrm{O}_{2} \mathrm{D}_{2} \mathrm{O}$ subphase $(\mathrm{O}), 0.014 \mathrm{M} \mathrm{KCl}(\bullet), 0.137 \mathrm{M}$ $(\mathbf{\square}), 0.67 \mathrm{M}(+), 1.50 \mathrm{M}(\bullet), 2.50 \mathrm{M}(\mathbf{\Delta})$. The curves for $0.137 \mathrm{M}, 0.67 \mathrm{M}, 1.50$ $\mathrm{M}$, and $2.50 \mathrm{M}$ have each been displaced vertically by $1 \times 10^{-10}$ for clarity. The curves through the data correspond to best-fits using analysis method I. No signal was detected at the lowest salt concentration. (b) Best-fit segment concentration profiles corresponding to

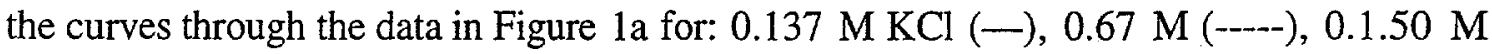
$(-), 2.50 \mathrm{M}(\cdots \cdots \cdot)$. (c) Best-fit scattering density profiles using analysis method $\mathrm{II}$.

Figure 2. (a) Neutron reflectivity data from dilute PSS56 solutions $(0.001 \mathrm{~g} / \mathrm{ml})$ with varying $\mathrm{KCl}$ concentration: pure $\mathrm{H}_{2} \mathrm{O}_{2} \mathrm{D}_{2} \mathrm{O}$ subphase $(\mathrm{O}), 0.014 \mathrm{M} \mathrm{KCl}(\bullet), 0.137 \mathrm{M}$ $(\mathbf{\square}), 0.67 \mathrm{M}(+), 1.50 \mathrm{M}(\bullet), 2.50 \mathrm{M}(\mathbf{\Delta})$. The curves for $0.137 \mathrm{M}, 0.67 \mathrm{M}, 1.50$ $\mathrm{M}$, and $2.50 \mathrm{M}$ have each been displaced vertically by $1 \times 10^{-10}$ for clarity. The curves through the data correspond to best-fits using analysis method I. No signal was detected at the lowest salt concentration. (b) Best-fit segment concentration profiles corresponding to

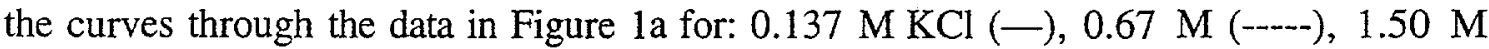
$(-), 2.50 \mathrm{M}(\cdots \cdots . .$.$) . (c) Best-fit scattering density profiles using analysis method \Pi$.

Figure 3. (a) Neutron reflectivity data from a dilute PSS 1150 solution $(0.001 \mathrm{~g} / \mathrm{ml})$ with $2.50 \mathrm{M} \mathrm{KCl}$. The data are compared with the best-fit curves using analysis method II and (-) a function consisting of a parabola with an exponential tail where the derivative is not constrained to vary smoothly from the parabola to the exponential decay, and (----) a function consisting of a single parabola followed by an exponential tail, where the derivative is constrained to vary smoothly from the parabola to the exponential decay. (b) Best-fit profiles corresponding to the curves in (a). The lines have the same meaning as in (a). This comparison indicates that a distinct second layer is required in the profile.

Figure 4. (a) Neutron reflectivity data from a dilute PSS56 solution $(0.001 \mathrm{~g} / \mathrm{ml})$ with 2.50 $\mathrm{M} \mathrm{KCl}$. The data are compared with the best-fit curves using analysis method II and ( - ) a function consisting of the sum of two parabolas combined with an exponential tail, and (----) a function consisting of a single parabola followed by an exponential tail, where the derivative is constrained to vary smoothly from the parabola to the exponential decay. (b) Best-fit profiles corresponding to the curves in (a). The lines have the same meaning as in (a). This comparison indicates that a distinct second layer is required in the profile. 
Figure 5. The adsorbed amount $\Gamma$ at the air surface of the aqueous subphase as a function the square root of $\mathrm{KCl}$ concentration for PSS56 (O) and PSS1150 (๑).

Figure 6. The thickness of the adsorbed layer as a function of $\mathrm{KCl}$ concentration for PSS56 (O) and PSS1150 (๑).

Figure 7. Surface tension of pure aqueous salt solutions $(O)$ and with $0.001 \mathrm{~g} / \mathrm{ml}$ PSS1150 ( The difference in surface tension at a given $\mathrm{KCl}$ concentration indicates the surface pressure due to the adsorbed PSS.

Figure 8. Relationship between surface pressure and adsorbed amount of PSS1150 from the data in Figure 5 and Figure $7 . \mathrm{KCl}$ concentration is the independent variable and increases along the abscissa. 


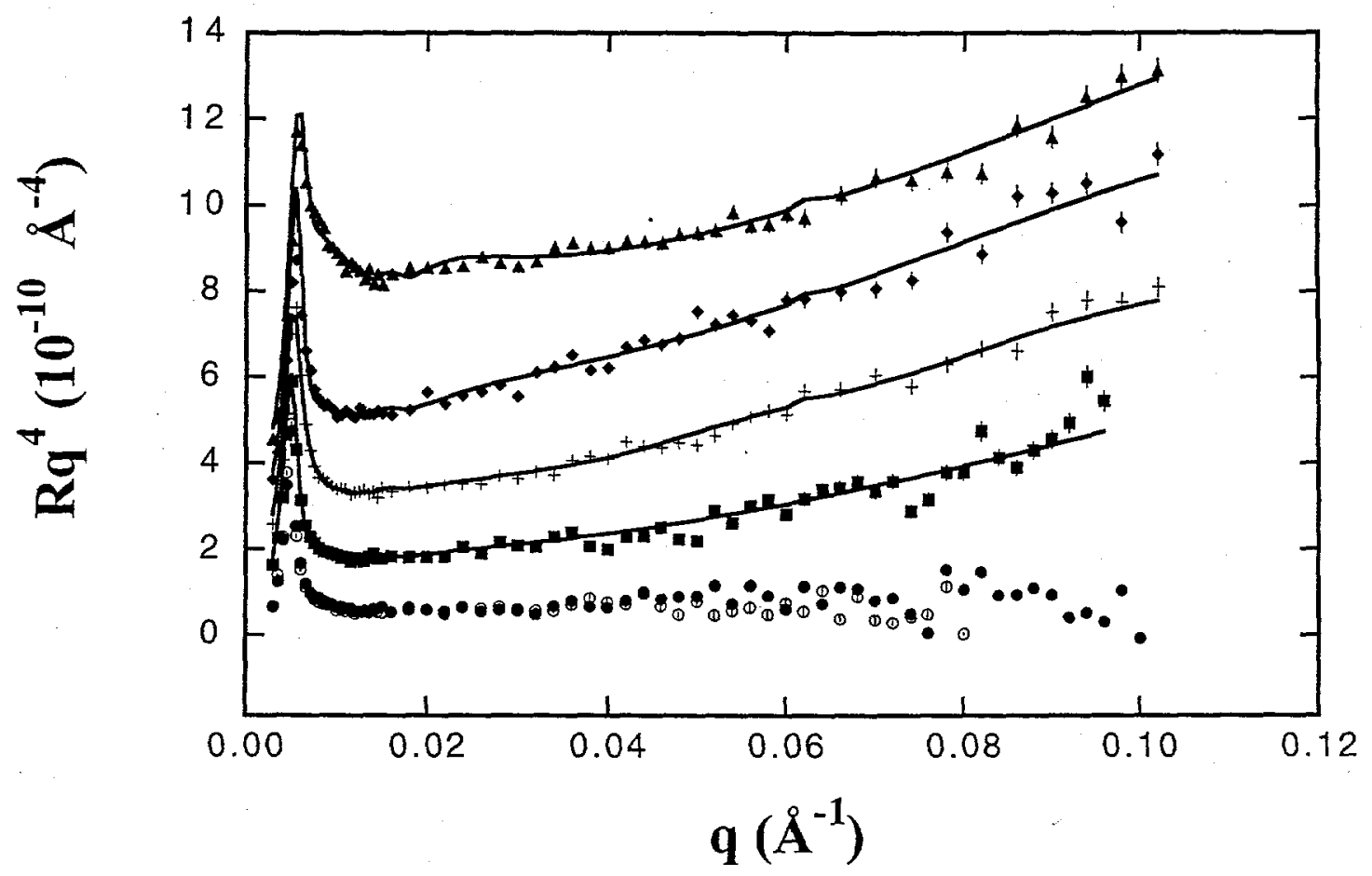




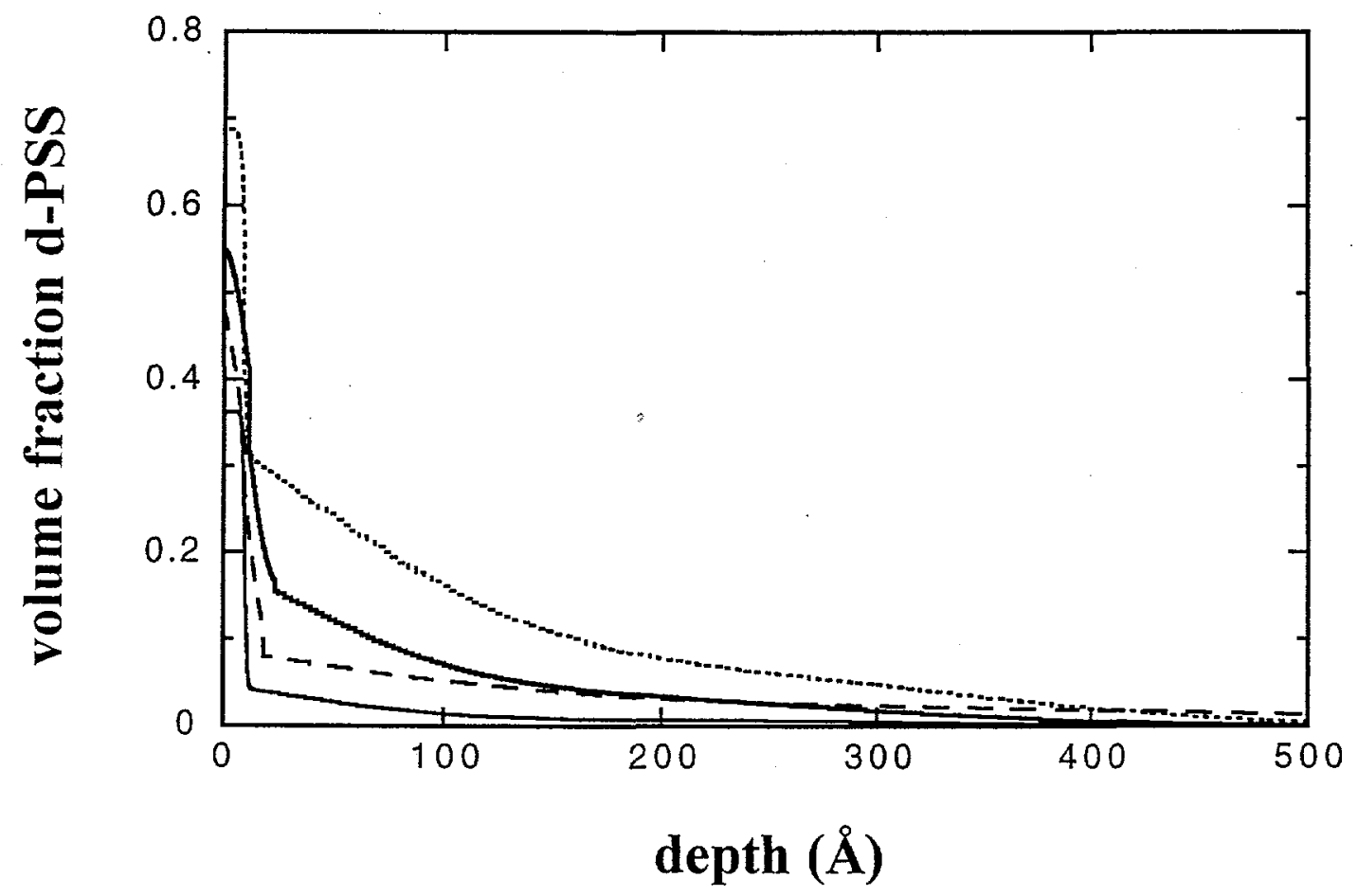




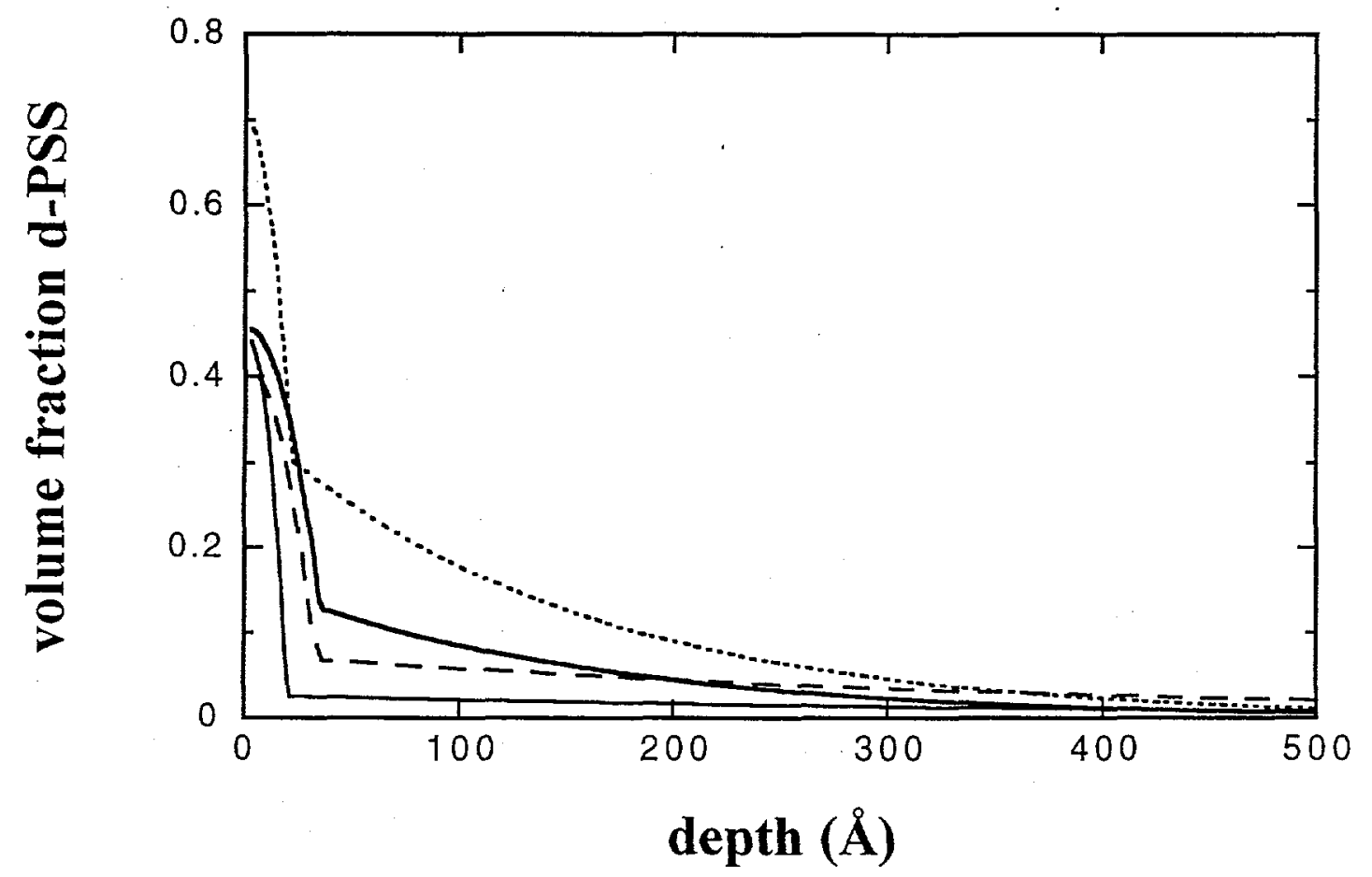




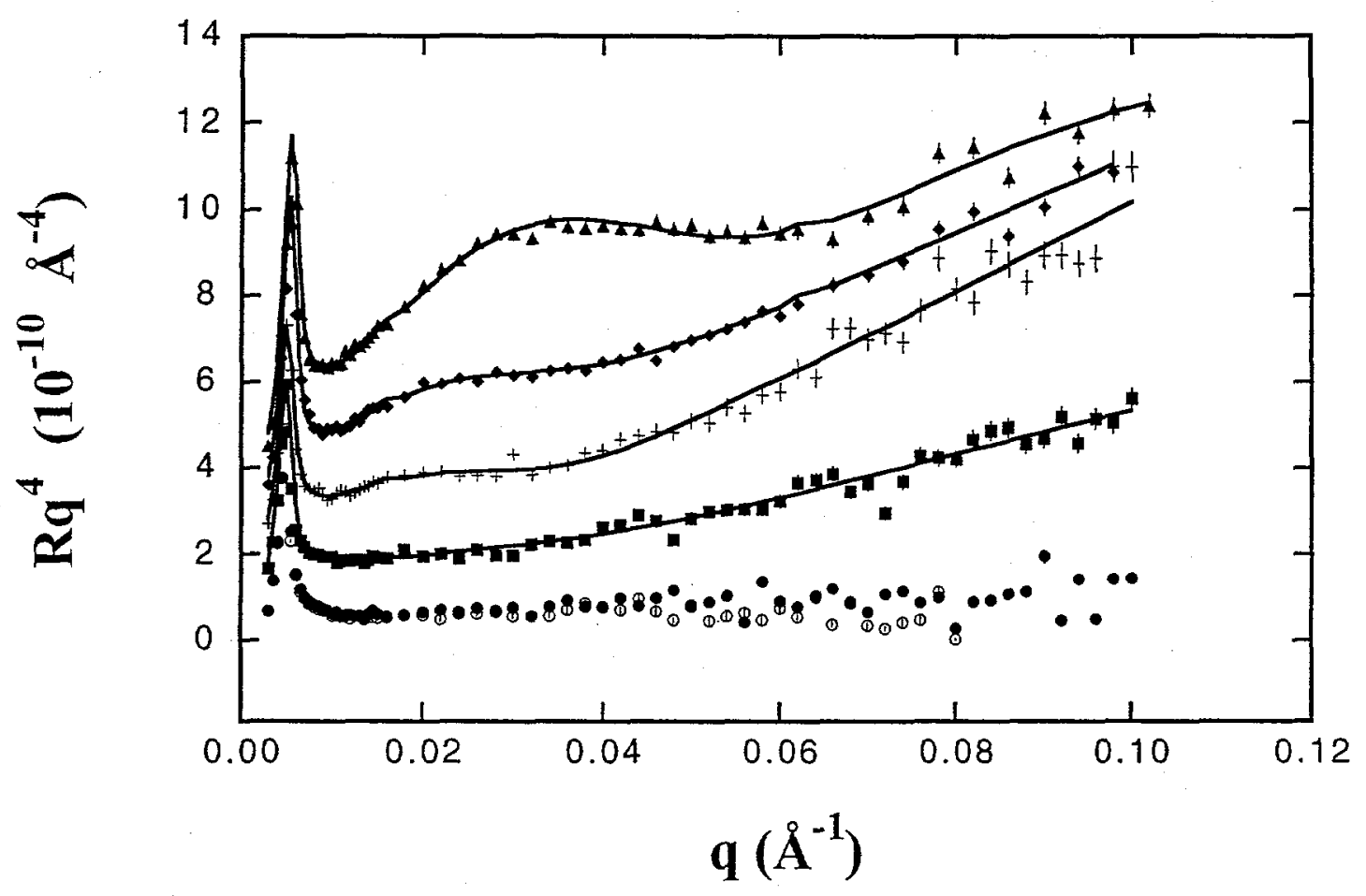

$2 a$ 
volume fraction d-PSS

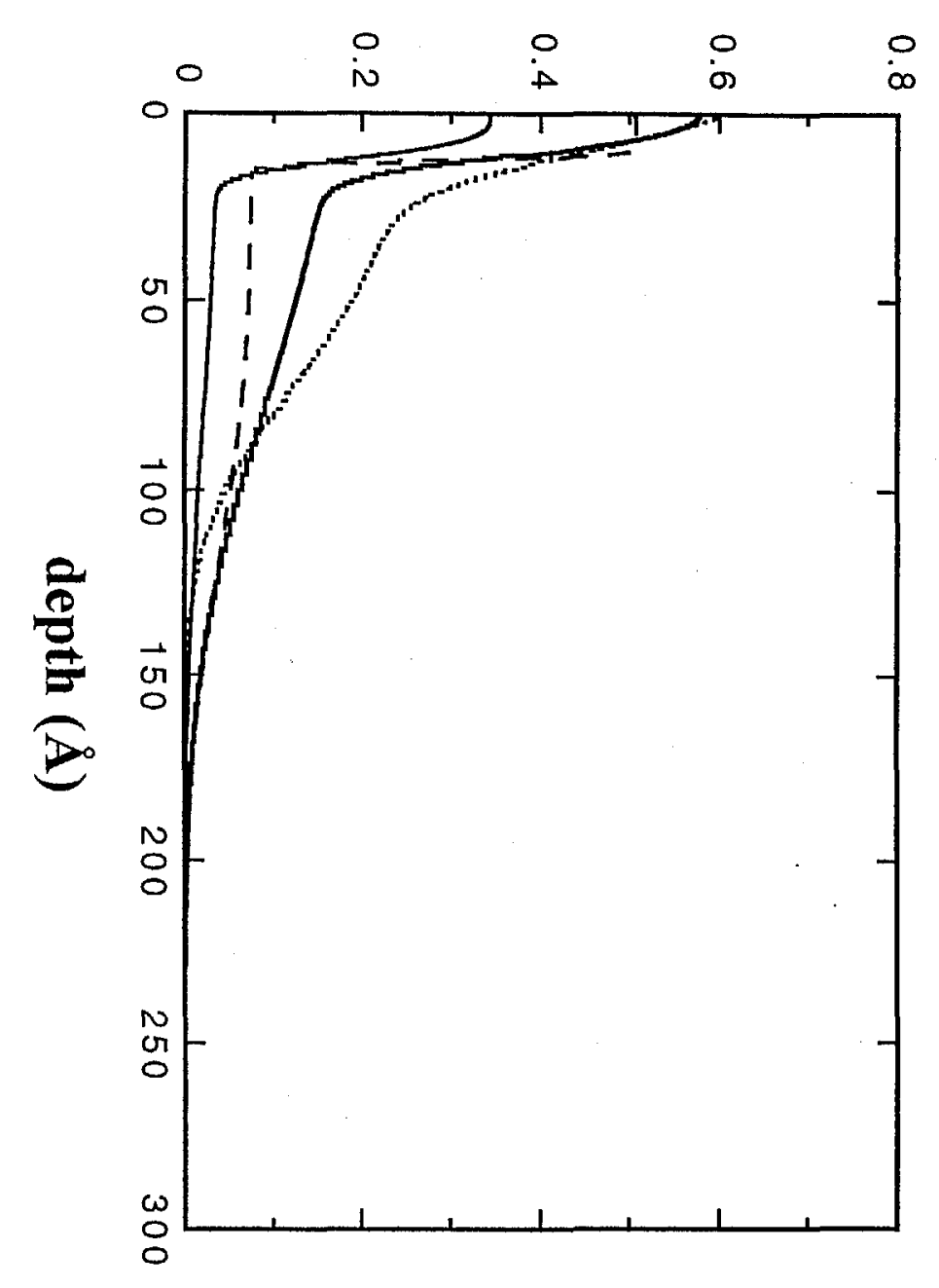

$\infty$ 


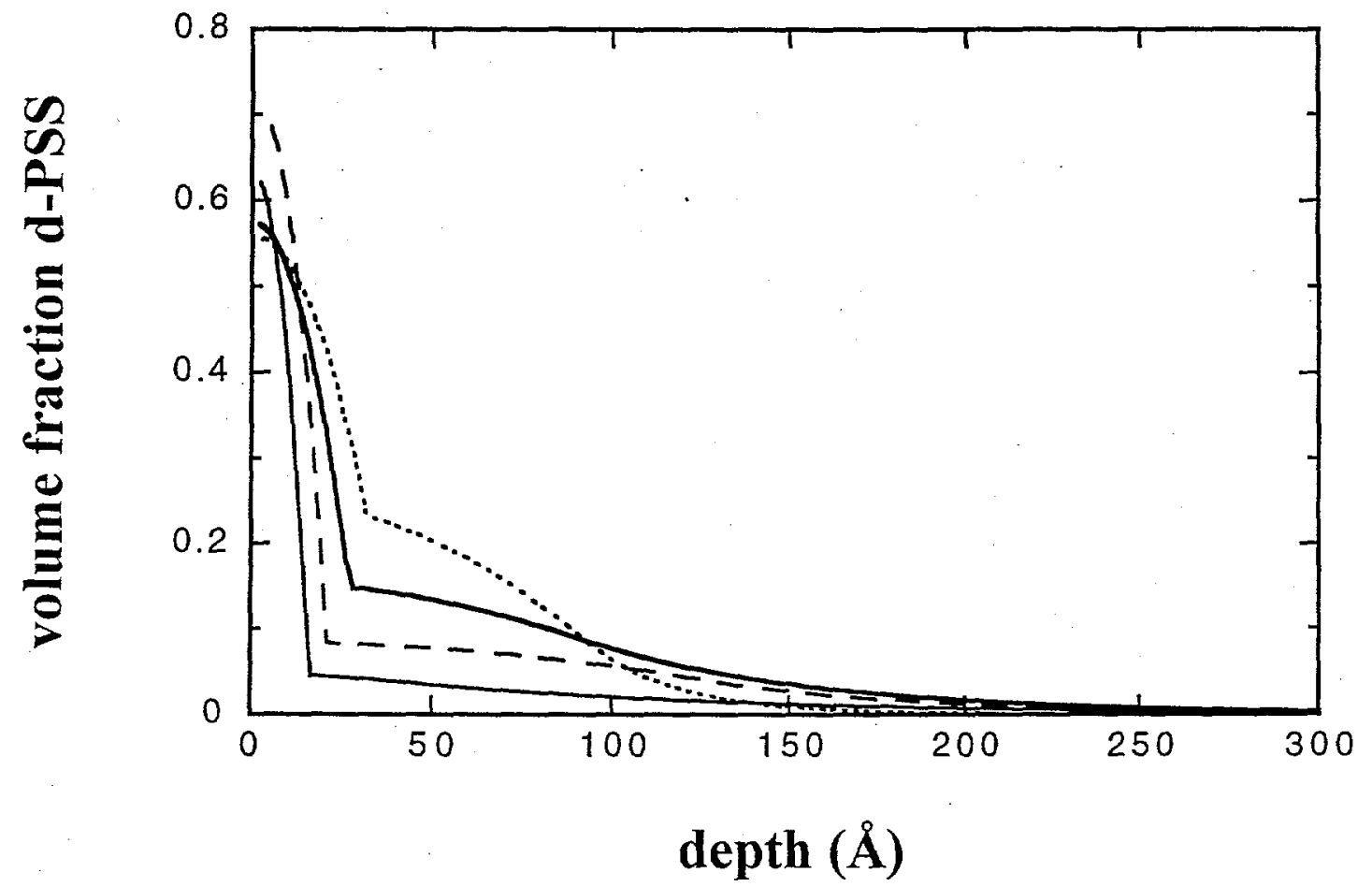

$2 c$ 


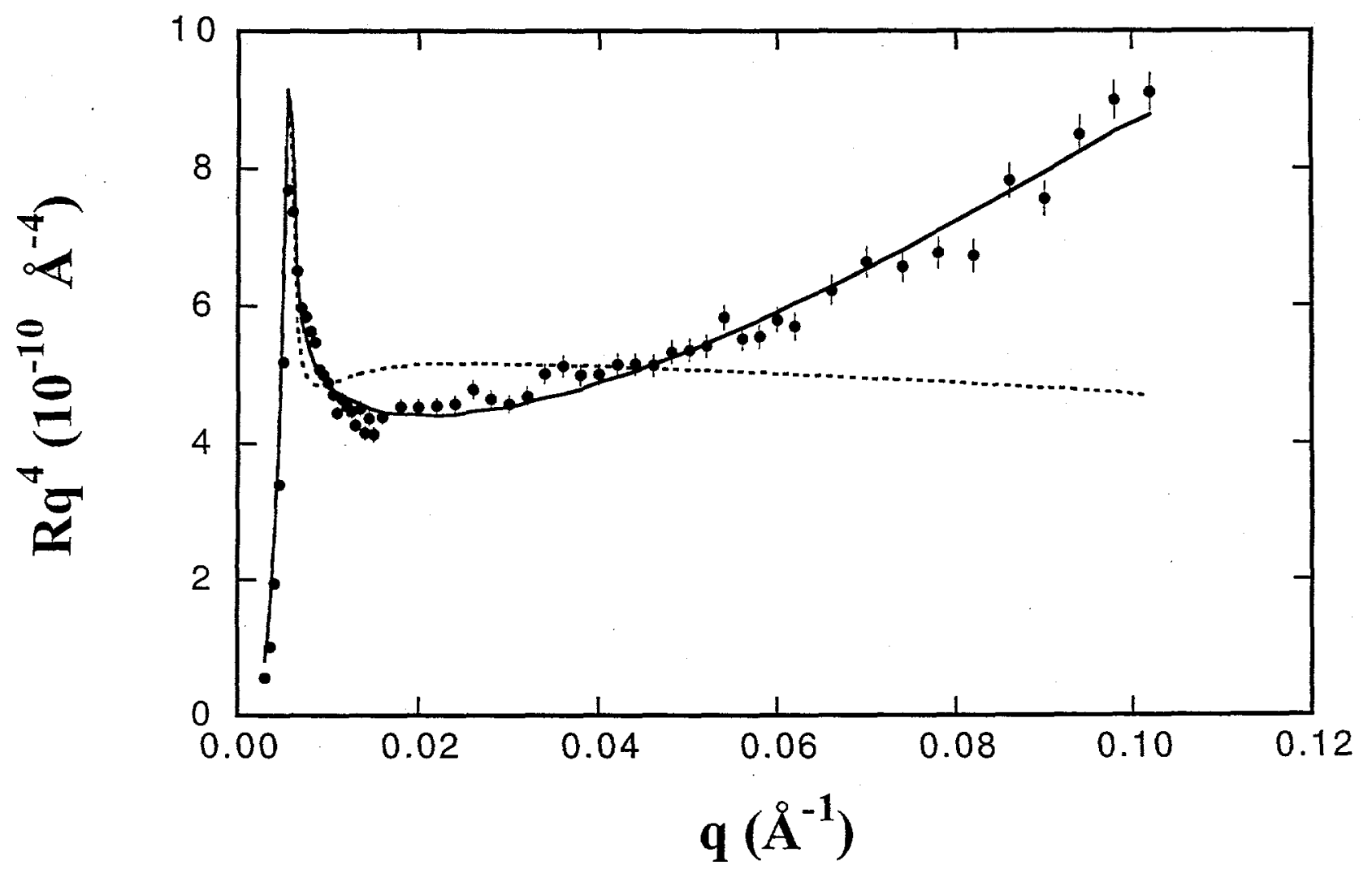

$3 a$ 


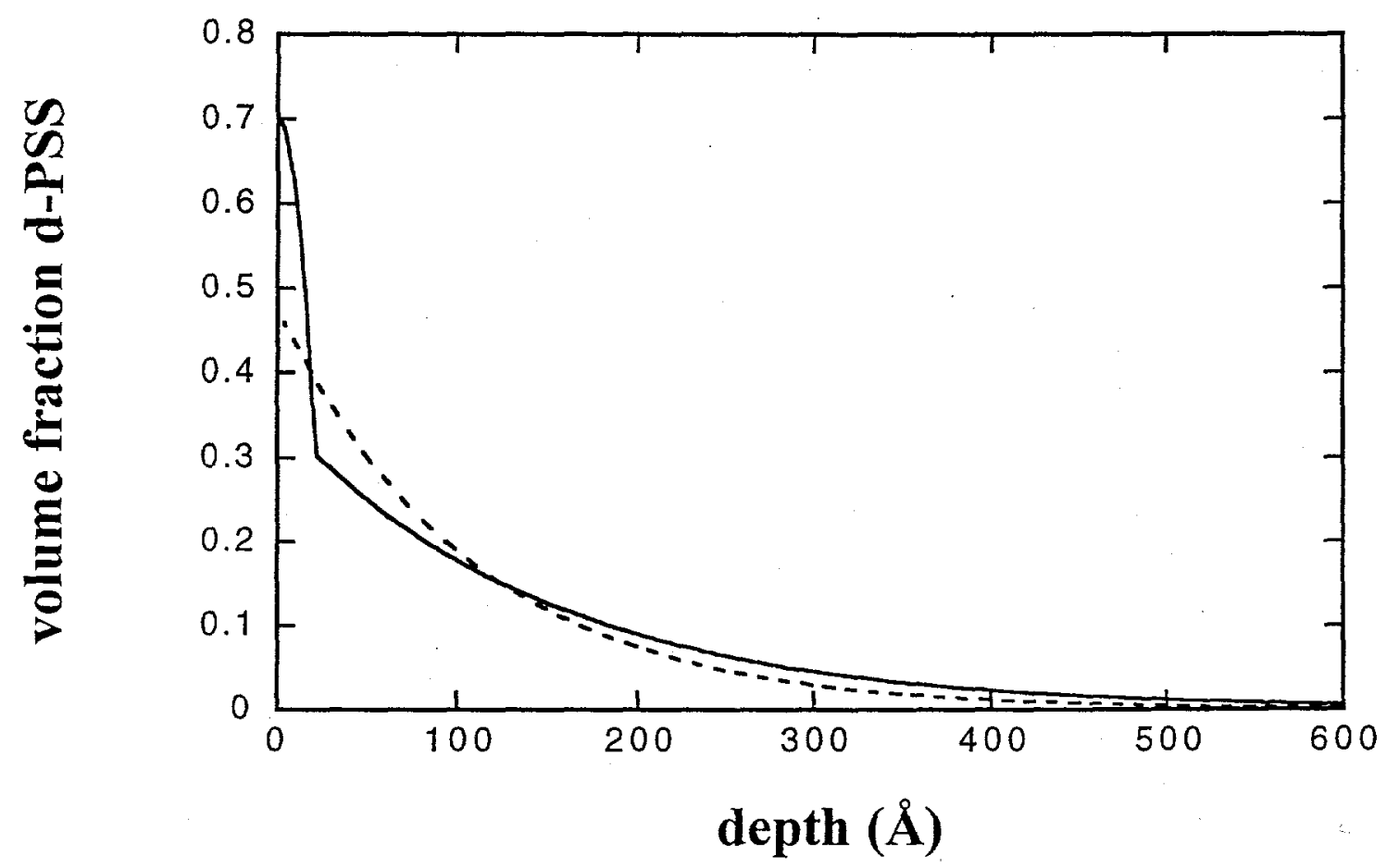




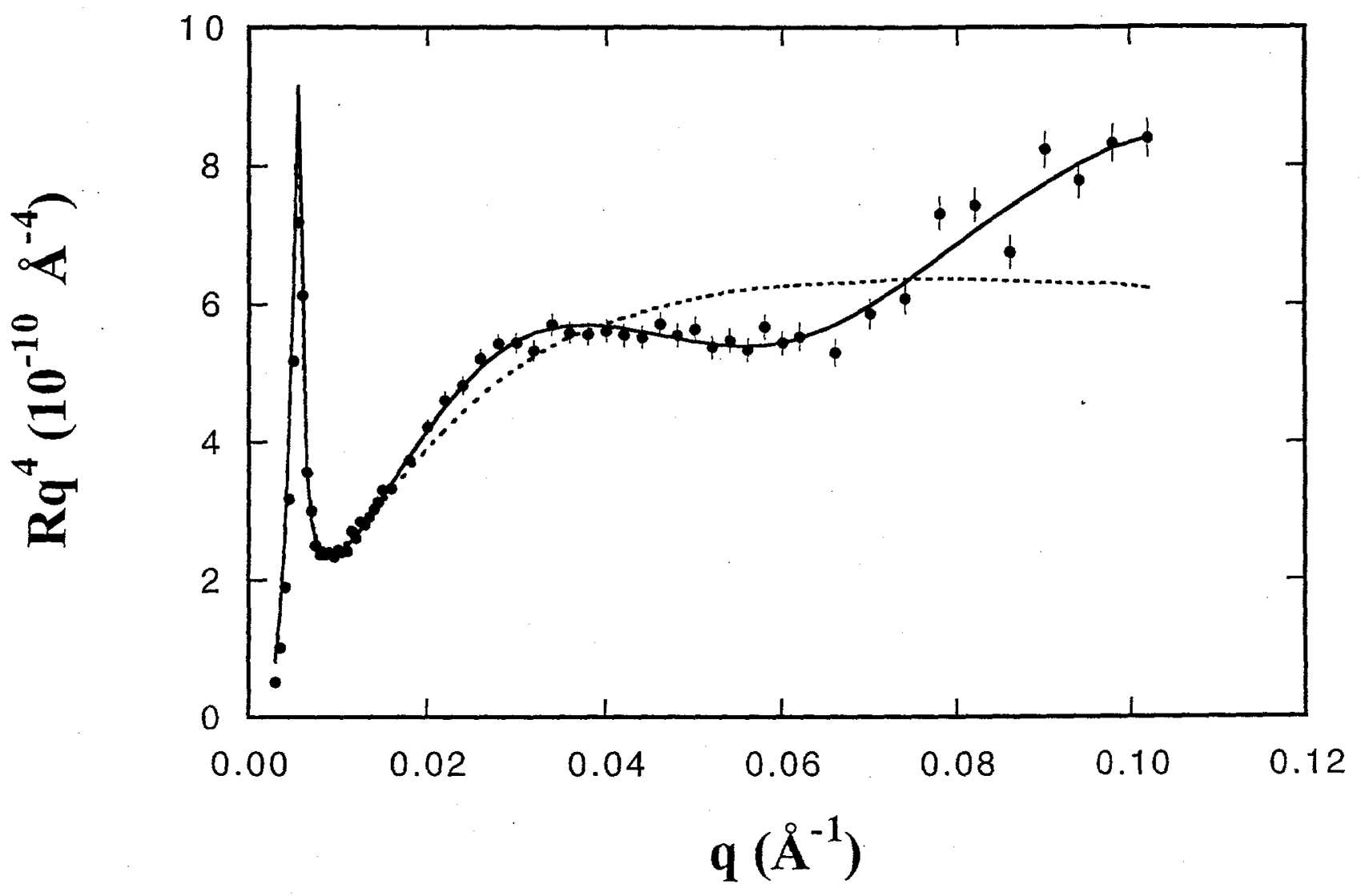

$4 a$ 


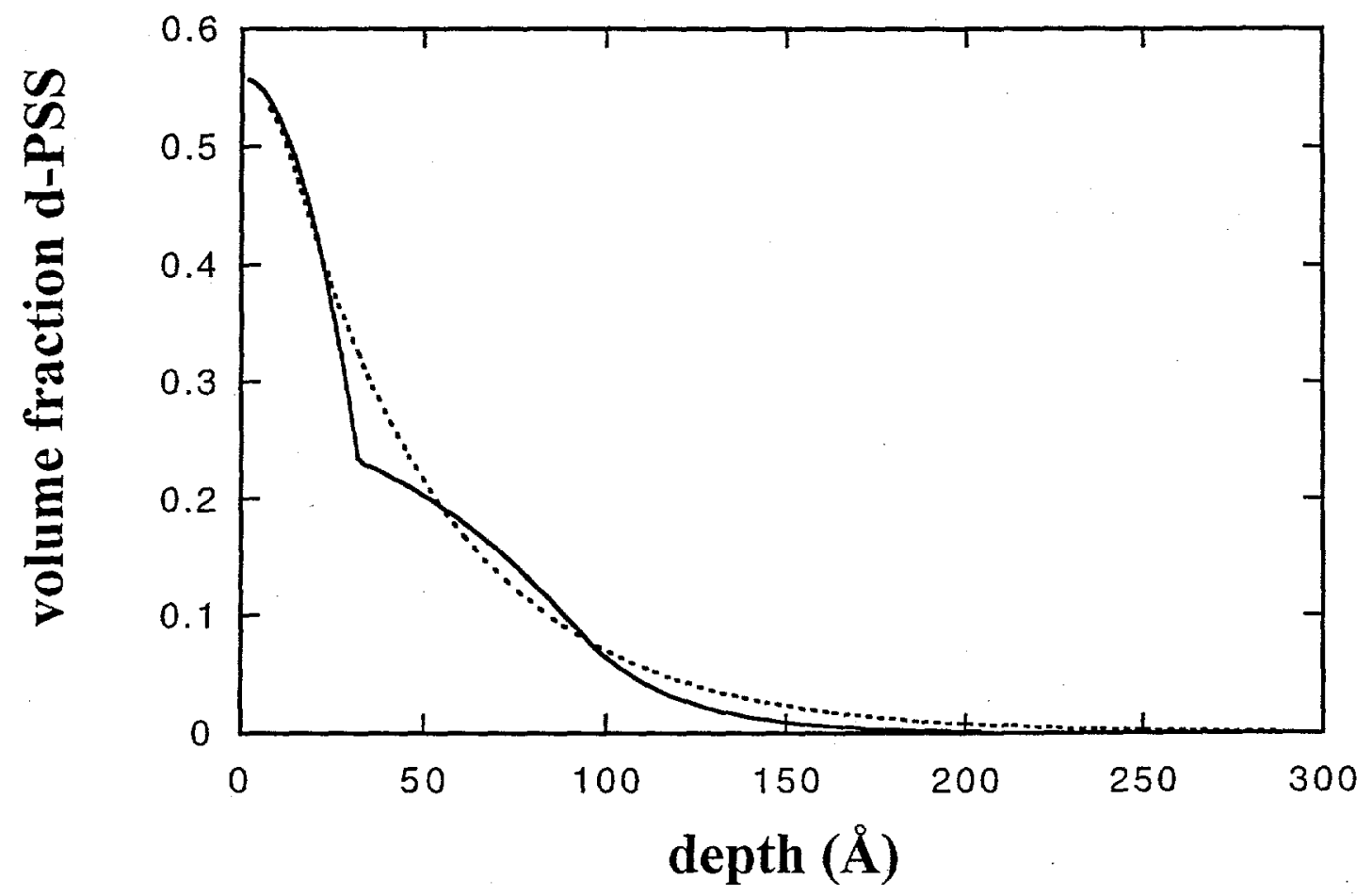

$4 b$ 


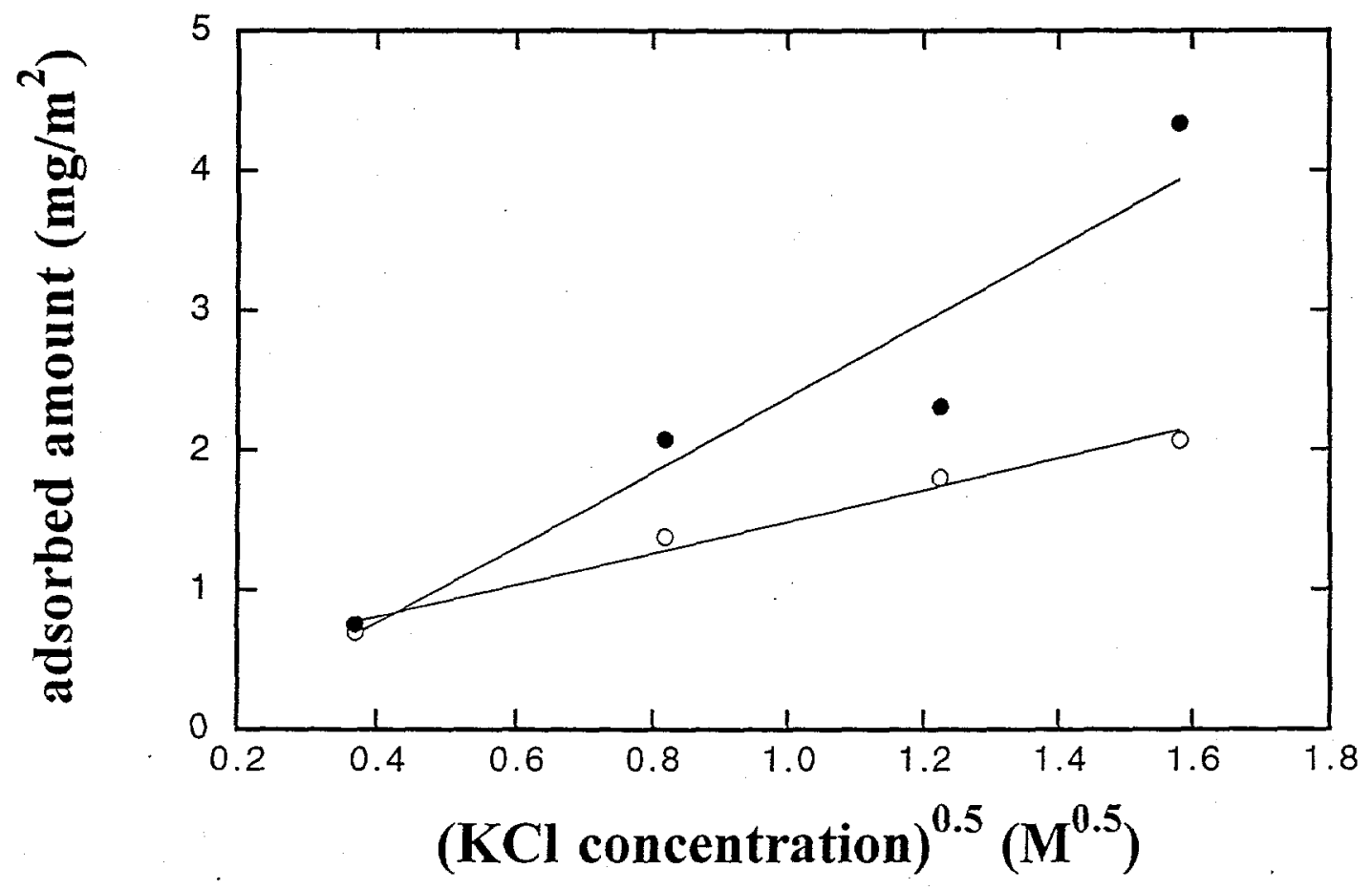

5. 


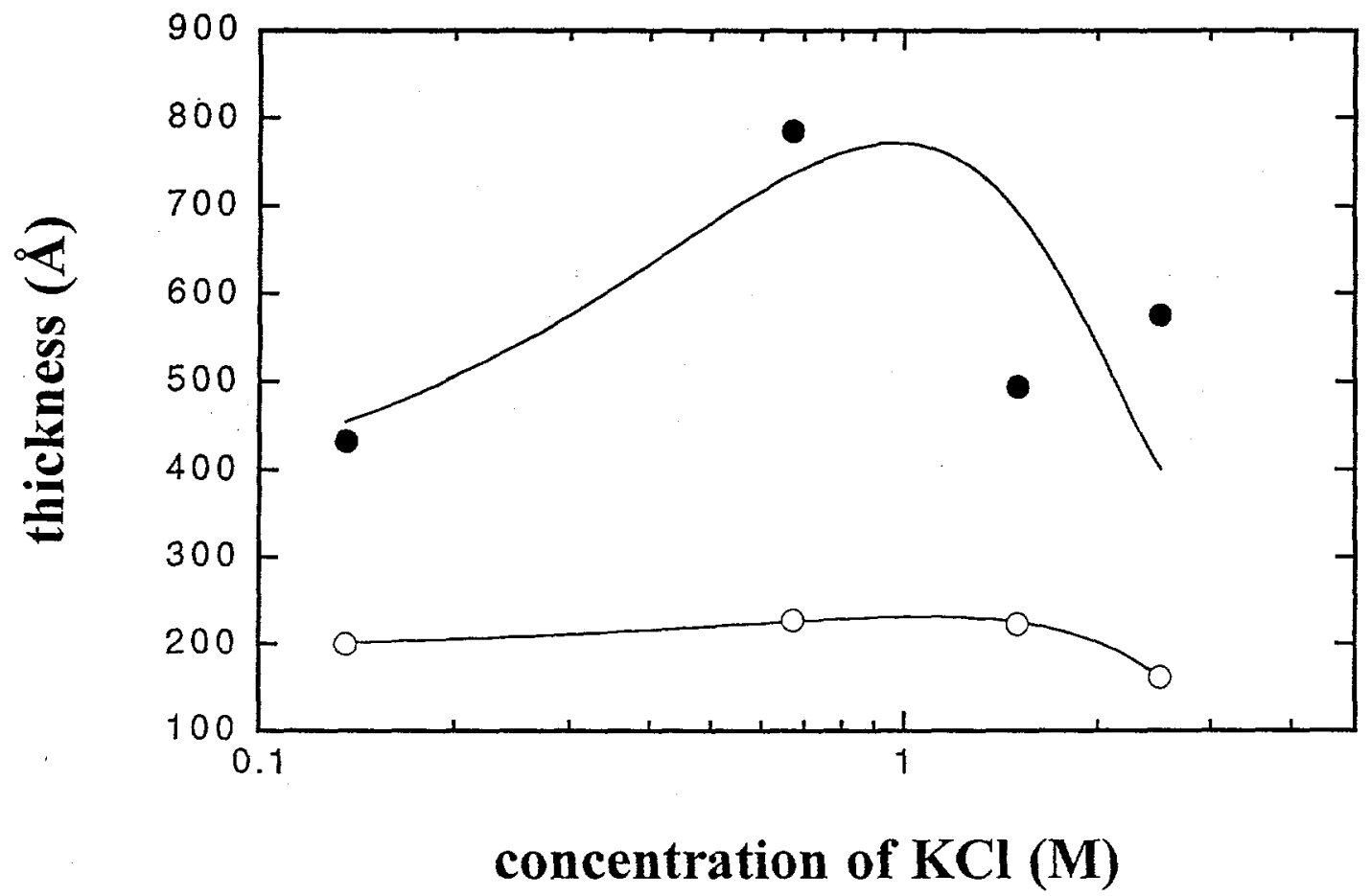




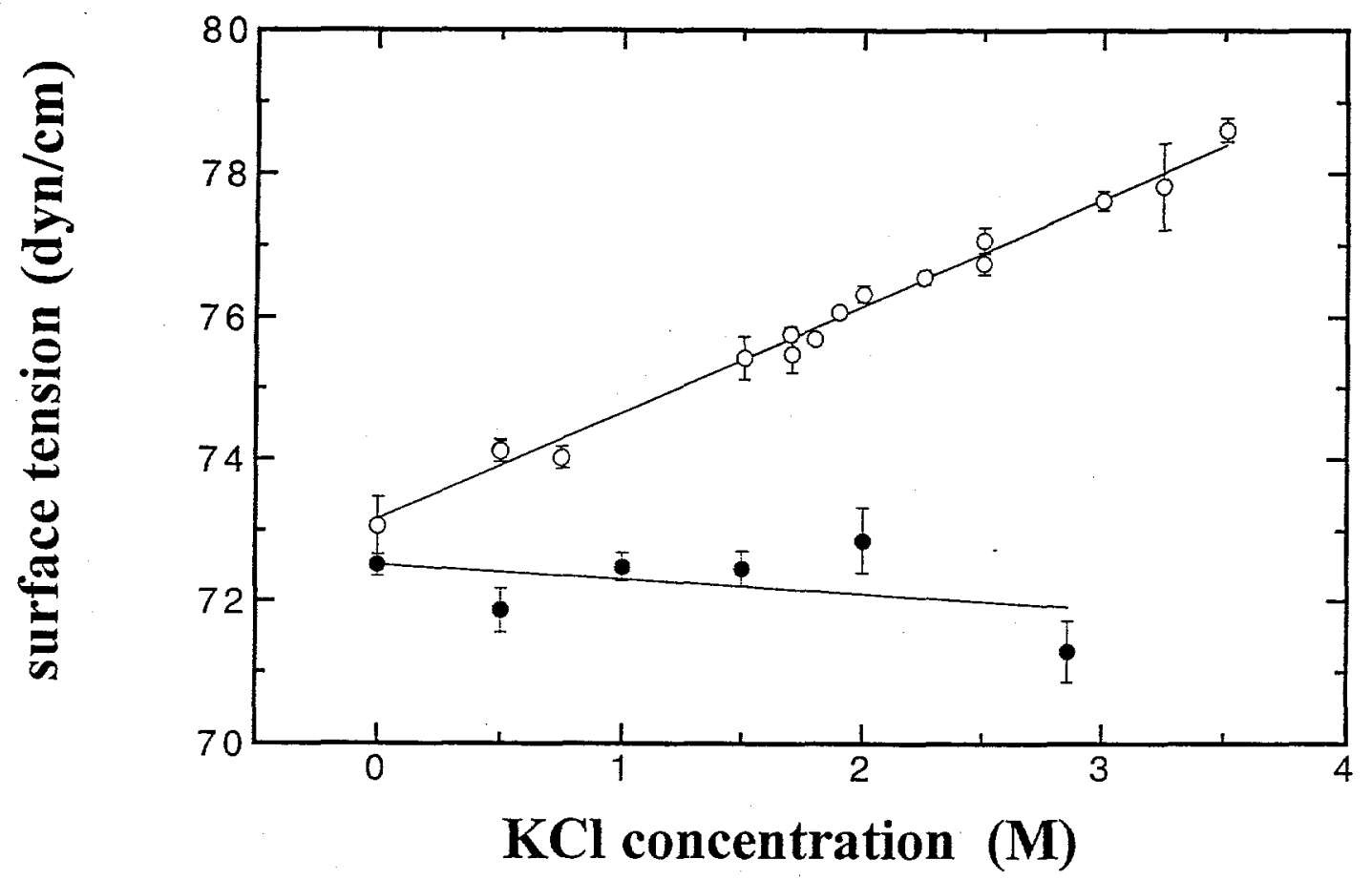




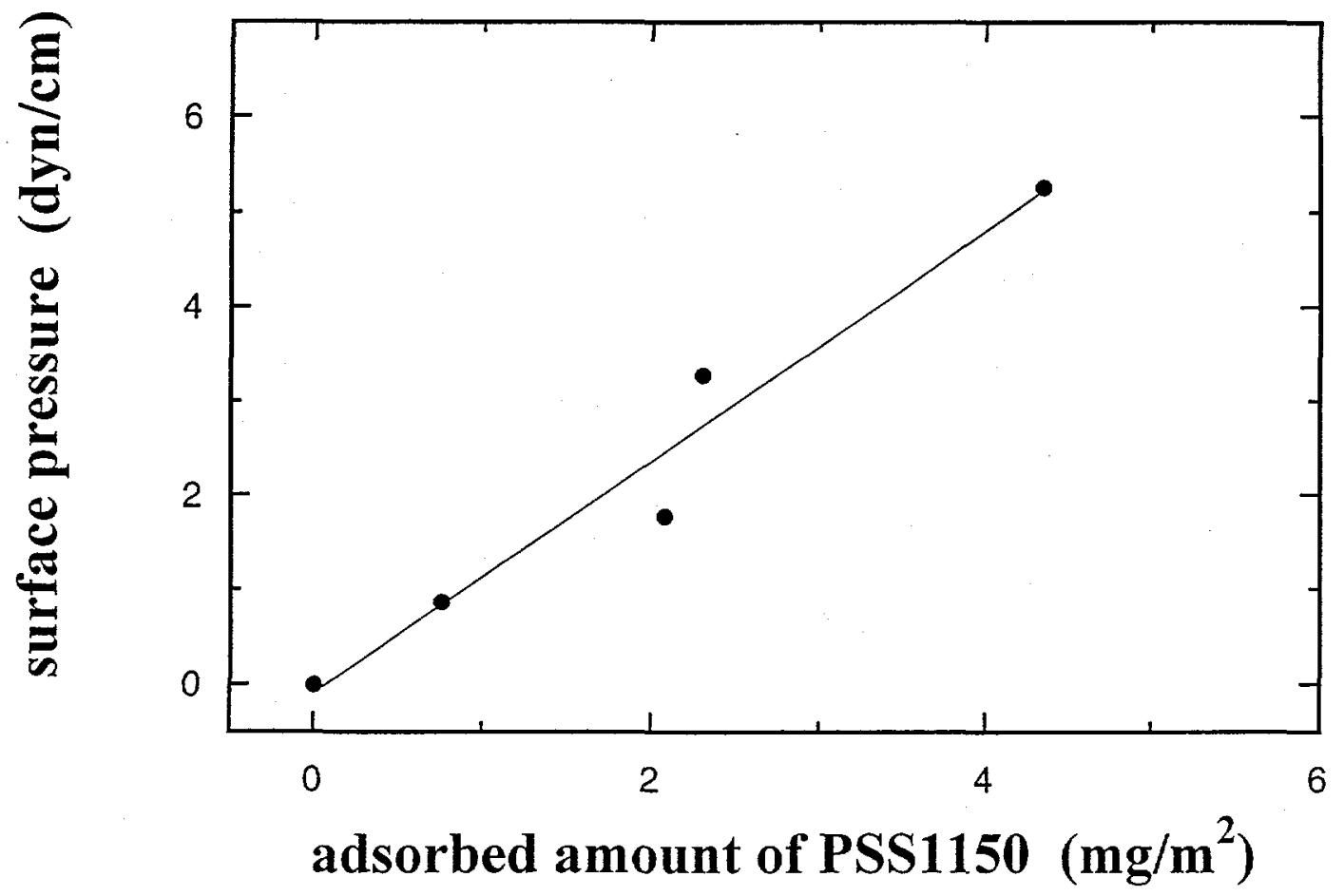

8. 